\title{
Trends of permanent pacemaker implantation in University Cardiac Center, BSMMU.
}

\author{
Fazlur Rahman, ${ }^{1}$, Syed Ali Ahsan ${ }^{1}$, Chaudhury Meshkat Ahmed ${ }^{1}$, Md. Safiuddin ${ }^{1}$, K.M.H.S.Sirajul \\ Haque $^{1}$, Sajal Krishna Banerjee1, Md. Abu Siddique1, Manzoor Mahmood ${ }^{1}$, Khairul Anam¹, \\ Md. Mukhlesur Rahman'1, S.M. Mostafa Zaman'1, Md. Khurshed Ahmed', S.M. Ahsan Habib1, \\ M.A. Salim¹, Mir J. Uddin², Mohammed Faruque ${ }^{3}$, M. A. Khali1 ${ }^{3}$, M. A. Patuari ${ }^{5}$, Md. Abdur \\ Rashid ${ }^{4}$ and G.. Hafiz. ${ }^{6}$ \\ ${ }^{1}$ Department of Cardiology, Bangabandhu Sheikh Mujib Medical University, Shahbag, Dhaka. \\ ${ }^{2}$ Department of Cardiology, Sir Salimullah Medical College Hospital, Dhaka. \\ ${ }^{3}$ Department of Cardiology, Dhaka Medical College Hospital, Dhaka. \\ ${ }^{4}$ Department of Anatomy, Bangladesh Medical College, Dhaka. \\ ${ }^{5}$ Department of Cardiology, National Institute of Cardiovascular Diseases, Dhaka. \\ ${ }^{6}$ Department of Pediatrics, Bangabandhu Sheikh Mujib Medical University, Shahbag, Dhaka.
}

Address for correspondence :

Dr. A.K.M. Fazlur Rahman, Associate Professor (Interventional Cardiology) UCC, BSMMU, Dhaka.

E-mail :drakmfrahman@yahoo.com

\begin{abstract}
The purpose of the study was to investigate the trends of permanent pacemaker implantations in the University Cardiac Center (UCC), Bangabandhu Sheikh Mujib Medical University (BSMMU), Dhaka. This retrospective study conducted in the department of Cardiology, UCC, BSMMU, Dhaka to evaluate demographic distribution, indications, complications of the permanent pacemaker (PPM) implantation and its hospital outcome. Data of this retrospective study was collected from hospital registry and patient's record files. Total 98 patients were studied. Among them male were $64.28 \%(\mathrm{n}=63)$ and female were $35.71 \%(\mathrm{n}=35)$. Most of them were elderly patients $(58 \%)$. Complete heart block was the most common cause for PPM implantation, which was $67.35 \%(\mathrm{n}=66)$. Single chamber multiprogrammable PPM (VVI) was implanted in $86.73 \%$ $(\mathrm{n}=85)$ and Dual chamber PPM (DDI) was implanted in $13.26 \%(\mathrm{n}=13)$ cases. No Major complications occurred during the procedure and short term in-hospital outcome was good for all the cases. This study showed that PPM implantation is rapidly increasing modality of treatment for patients with cardiac bradyarrhythmias as effective technique with good in- hospital outcome.
\end{abstract}

\section{Introduction}

The fundamental principles for the utilization of an artificial pace maker were established as early as 1932 by Hymen and later by Collaghan and Bigelow in 1951. First pacemaker implantation was done in 1958. In Bangladesh, pacemakers are being implanted since 1980 s. The number of pacemaker implantation centers as well as number of patients required for treatment with PPM is increasing day by day in this country. In BSMMU pacemaker implantation started since 2003. Since then, it is offering special services providing modern technique to the patients of PPM of this centre. Cardiac Pacemaker is a device which delivers battery supplied electrical stimuli over lead with electrodes in contact with the heart. ${ }^{1}$ Cardiac Pacing can ensure immediate and reliable electric control of the heart rate in case of cardiac bradyarrhythmias and to correct hemodynamic disturbances. ${ }^{2}$ According to chamber paced, pace- makers are of two types-single chamber pacing and dual chambers pacing. ${ }^{3} \mathrm{~A}$ recent survey of medical pacemakers in the USA found that $60 \%$ of pacemakers are dual chamber, $70 \%$ are rate adaptive and $30 \%$ have both capabilities. ${ }^{4}$ The decision to implant a permanent pacemaker is an important one that involves the pacemaker specialist, the primary physician and the patient. It is critical that the need for pacing be clearly documented accordingly.

\section{Materials and methods}

This retrospective study was done on population samples who were admitted in the cardiology department of UCC, BSMMU for the treatment of various cardiac arrhythmias. e. g. $\mathrm{CHB}, 2^{\circ} \mathrm{HB}$, bifascicular or trifascicular block, and Sick Sinus Disease during the period of July 2003 to June 2007. Patients were selected consecutively. Patient's various data e.g. age, gender, risk factors, symptoms, indica- 
tion and type of PM implantation, early and late complications were collected from hospital registry, patient's record files and information from performing interventionist. Parameters of this study were plotted in preformed data sheet and statistical analyses of variables were performed by using SPSS versions 12.0.

\section{Results}

Total ninety eight (98) patients were studied. Among them $64.28 \%(n=63)$ were male and $35.71 \%(n=35)$ were female. Majority of the patients were in the age group of 40-49 years $(37.71 \%)$.

Table-I: The baseline characteristics of the study population:

\begin{tabular}{lll}
\hline Variables & & Number (\%) \\
\hline Demogphaphics- & Male & $63(64.2 \%)$ \\
Risk factors & Elderly >60yrs & $35(35.8 \%)$ \\
& IHD & $58(59.0 \%)$ \\
HTN & $10(10.2 \%)$ \\
DM & $68(69.3 \%)$ \\
Indication & Drugs & $54(55.1 \%)$ \\
& CHB & 0 \\
& $2^{0}$ HB & $66(67.4 \%)$ \\
& Bifascicular block & $4(4.1 \%)$ \\
& Trifascicular block & $4(4.1)$ \\
& Symptomatic Bradycardia & $2(2.0 \%)$ \\
Type of PPM & SSS & $17(17.4 \%)$ \\
& Single chamber & $85(86.7 \%)$ \\
& Dual chamber & $13(13.3 \%)$ \\
\hline
\end{tabular}

IHD-Ischemic Heart Disease; HTN-Hypertension; CHD-Complete Heart Block; $2{ }^{0}$ HB-Second Degree Heart Block; SSS-Sick Sinus Syndrome.

Among the all patients, 59\% $(\mathrm{n}=58)$ was elderly and had degenerative disease, $10.2 \%(\mathrm{n}=10)$ had ischemic heart disease, 69.3\% $(n=68)$ had hypertension and 55.1\% $(n=54)$ had diabetes mellitus.

Figure-1: Distribution of indications of PPM implantation

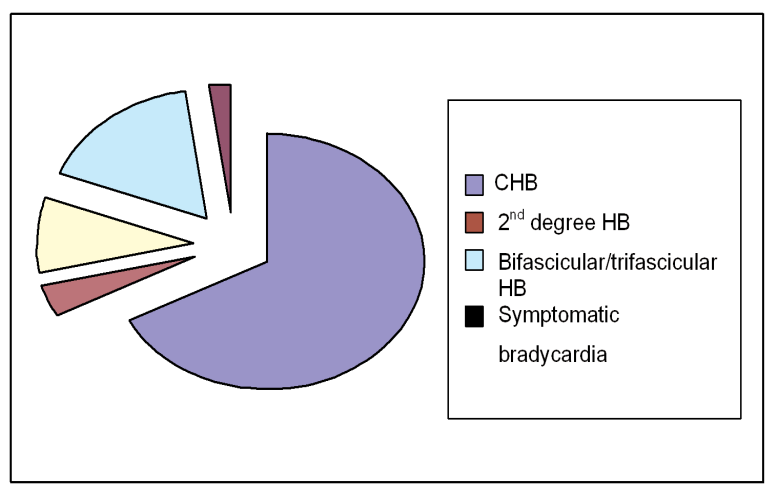

Complete heart block (CHB) was the most common cause for PPM implantation which was $67.35 \% \quad(n=66)$. Indication of PPM for Sick Sinus Syndrome (SSS) patients were $17.35 \%(\mathrm{n}=17)$, for symptomatic $2^{0}$ Heart block $\left(2^{0}\right.$ HB) was $4.08 \%(n=4)$, for bifascicular or trifascicular block was $9.18 \%(\mathrm{n}=9)$ and for symptomatic bradycardia was $2.04 \%(\mathrm{n}=2)$.

\section{Figure 2: Type of PPM implanted}

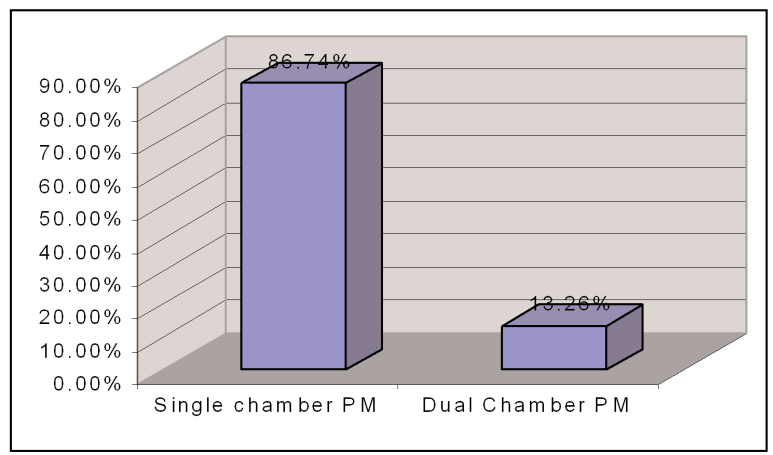

Single chamber multiprogrammable PPM (VVI) was implanted in case of $86.73 \%(\mathrm{n}=85)$ and Dual chamber PPM (DDI) was implanted in $13.26 \%(\mathrm{n}=13)$ cases.

\section{Discussion}

Once the decision has been made to implant a pacemaker in a given patient, the clinician must decide among a large number of available pacemaker generators and leads on the basis of i) underlying rhythm disturbances, ii) overall physical disturbances, iii) associated medical problems, iv) exercise capacity, v) chronotropic response to exercise, vi) effect of pacing mode on long term morbidity and mortality. Other factors that importantly influence the choice of pacemaker system components include the capabilities of the pacemaker programmer, which provide the link between the pacemaker system the physician and local availability of technical support.

Some of the guidelines for choice of pacemaker generator in selected patients: ${ }^{6}$

1. With normal AV node and Purkinje fibers: AAI, AAIR,;

2. With AV involvement: DDD, DDDR, DDIR;

3. With AV block: VVI, VDD;

4. Carotid sinus syndrome: VVI, VDD, DDD, DDI;

5. HCM: DDD, DDDR.

Indications, type and mode of approach in the study population were more or less same with respect to other centers at home and abroad.

Pacemaker can cause complication at the time of implantation, with injuries to the heart, lungs, or blood vessels. These complications can be reduce by proper patients 
selection, preparation and careful operation of the procedure. After procedure common complications are infection, PM malfunction e. g. irregular pacing, run-away or slowing of PM; PM failure e. g. battery depletion, lead dislodgment (should be less than 1-2\%); circuit failure e. g. loose connector pin, lead fracture, insulation break; Infection and erosion (should be less than $2 \%$ ). Late complications can be minimized or managed by properly careful follow up of patients, which should include evaluation of patient's symptoms, assessment of battery status, pacing threshold, pulse width, sensing function and lead integrity. ${ }^{7}$

Most of the pacemakers were implanted transvenously through the cephalic veins and rest of them through subclavian vein with the pulse generator placed in the upper anterior portion of the chest. No major complications occurred during the procedures and in-hospital stay. The overall short term e.g. in hospital outcome was good of the study population.

\section{Conclusion}

Techniques of cardiac pacing have advanced remarkably since this therapy was introduced almost four decades ago. Although the current generation of pacemaker seems more than adequate to meet the needs of most patients, the device therapy is now rapidly expanding with implantable devices for haemodynamic monitoring and heart failure therapy. The rapid technological advancements in cardiac pacemaker devices have at least to some extent served as a catalyst for an even faster evaluation in implantable cardioverter defibrillation (ICD) and cardiac resynchronization therapy (CRT) devices. After successful pacemaker implantation, innovation for clinical trial of implantation of ICD and CRT is expected. Clinical trials are an integral part of the discipline of implantable device therapy and will remain so as we see further innovative improvements in the years to come.

\section{References}

1. Serge BS, Douglas PZ: Cardiac pacemaker and antiarrhythmic devices. Braunwald's Heart Disease: A Text Book of Cardiovascular Disease. $7^{\text {th }}$ edition, Philadelphia. W.B. Suanders. 2006; 767.

2. Patney. NL et al. Management of Heart block in Acute Myocardial Infarction by Tranvenous Pacing. Indian Heart Journal 200; 2: 111.

3. Bloomfield P, Miller HC: Permanent pacing. B M J 1998: $295 ; 122$.

4. Serge BS, Douglas PZ: Cardiac pacemaker and antiarrhythmic devices. Braunwald's Heart Disease: A Text Book of Cardiovascular Disease. $7^{\text {th }}$ edition, Philadelphia. W.B. Suanders. 2006; 767.

5. Gregaratos AD, Abrams J, Epstein $\mathrm{AE}$ et al : ACC/AHA/NASPE 2002 guideline update for implantation of cardiac pacemakers and antiarrhythmia devices. Circulation 2002; 106: 2145.

6. Bloomfield P, Miller HC: Permanent pacing. B M J 1998: $295 ; 122$

7. Serge BS, Douglas PZ: Cardiac pacemaker and antiarrhythmic devices. Braunwald's Heart Disease: A Text Book of Cardiovascular Disease. $7^{\text {th }}$ edition, Philadelphia. W.B. Suanders. 2006; 767. 